\title{
Adaptive Significance of Play: Are We Getting Closer?
}

T.M. Caro

Life history theory predicts that animals whose activities impose time, energy or survivorship costs at one stage of their lives will subsequently suffer incremental decreases in fitness unless there are compensatory benefits. Play, a widespread activity among juvenile mammals and several orders of birds' appears costly, yet its adaptive significance is poorly understood despite over 15 years of detailed study $y^{2.3}$. Four issues have plagued understanding of the function of play: lack of a consensus on its definition, difficulties in selectively depriving animals of play opportunities and in meeting the challenge of interpreting negative results, paucity of empirical data on the costs of play, and failure to pay sufficient attention to field and naturalistic studies. Despite these problems, sex differences in play and partner preferences of participants now suggest that play serves to improve future adult motor skills in a number of species.

Since Karl Groos ${ }^{4}$ attempted to link the biology of play to human artistic activity, play has occupied the attention of observers of animal behaviour for 90 years. In the last 15 , research has crystallized over the issue of the adaptive significance of this widespread and conspicuous juvenile activity, yet several important problems have impeded significant advances in understanding. Here I review these issues and indicate promising avenues for future research.

\section{Definitions}

As every species plays somewhat differently, defining play by its structural qualities is a laborious procedure, and although some behaviour patterns are specific to play alone, this is not the case for every species, nor even every play bout. To tackle the problem of definition, Loizos $^{5}$ suggested that play patterns had certain structural criteria common to all species, such as the use of motor patterns from several functional contexts, exaggeration and repetition of motor acts, and

T.M. Caro is at the Evolution and Human Behavior Program, Rackham Building, University of Michigan, Ann Arbor, MI 48109-1070, USA. reordering of behavioural sequences. Nevertheless, subsequent critical examination of these criteria showed some to be absent from the play of certain species such as American black bears (Ursus americanus) ${ }^{6}$ and coyotes (Canis latrans) ${ }^{7}$.

Defining play by its function is also difficult at present; but because most people can informally agree as to whether an animal (or child ${ }^{8}$ ) is playing, and interobserver reliability in experimental situations is high", play is now defined either by the context in which it occurs ${ }^{10}$, or by working definitions which will be replaced once its functions are uncovered'!. One such definition is: 'Play is all locomotor activity performed postnatally that appears to an observer to have no obvious immediate ber,efits for the player, in which motor patterns resembling those used in serious functional contexts may be used in modified forms. The motor acts constituting play have some or all of the following structural features: exaggeration of movements, repetition of motor acts, and fragmentation or disordering of sequences of motor acts.' ${ }^{3}$

Careful choice of study animal, however, could circumvent the problem of definition: both harp seals (Phoca groenlandica) ${ }^{12}$ and dwarf mongooses (Helogale par$v_{\text {vula }}{ }^{13}$ make specific and easily recognizable vocalizations while playing, possibly reflecting the different neuroendocrine pathways involved in the production of play behaviour ${ }^{14}$. Though troublesome, lack of precision in defining play is now viewed as insignificant compared to the problems of determining its function.

\section{Experimental and correlational studies}

Numerous hypotheses have been proposed for the adaptive significance of play ${ }^{15}$ but they can be divided into three major categories: those that suggest that play serves as a mechanism to develop adult fighting and predatory skills as well as physical strength and endurance; those that regard play as a means of social bonding and acquisition of social and com. munication skills; and those that view play as a way of increasing individuals' cognitive and innova. tive abilities ${ }^{2}$. Most empirical stud. ies have focused on the first motor training - set of hypotheses partly because the other hypoth eses are more vaguely formulated social and cognitive skills are diffi cult to measure precisely, and be cause such skills are now regardec as only incidental benefits of plas by those who have weighed the evidence $^{2}$.

Three approaches have beer used to determine the function o play: (1) experimental manipula tion of early play experience, i.e giving lesser or greater opportuni ties for particular types of play; 12 searching for correlations betweer play and other types of behaviour usually exploiting natural variatior within populations; and (3) using the indirect 'argument from design approach, in which the observec structure of play is matched againsi the requirements of its suggested function.

Possibly the earliest experi. mental test of a play hypothesis was that of Thomas and Schaller ${ }^{i t}$ who raised kittens (Felis catus) in a visually barren enclosure, or with translucent goggles, and compared their predatory behaviour to that of control kittens at 11 weeks of age Results showed that the 'Kaspar. Hauser' experimental cats exhibited typical prey-catching movements in the same way as thei normally reared siblings, providing one of the first key findings concerning play: that play experience is not necessary for the develop. ment of many of the serious behaviour patterns seen in an animal's repertoire. Similarly, differences in the amount of play shown by free-living squirrel monkeys (Saimiri spp.) in different habitats were not associated with differences in social organization or adult behaviour $^{17}$.

Deprivation studies that limit the opportunities animals have for play often result in animals living in impoverished environments, without companions, and can cause considerable stress. To circumvent some of the confounding variables. Einon and colleagues ${ }^{18}$ raised rats 
in isolation but allowed them to interact with drugged partners, that played little, for an hour a day. Previously they had shown that rats raised in isolation differed in many resipects from those reared normally 19 but if they were allowed an hour of social contact per day they showed behaviour in open field tests intermediate between the two groups. Rats that played with drugged partners, however, subsequently behaved more like complete isolates - suggesting that the quality of social interaction was incleed important for later differences in behaviour, although whether this behaviour was play per se was unknown.

An alternative to selective play deprivation is to increase opporturities for play. To determine whether play improves adult skills, rather than being necessary for their appearance, Caro ${ }^{20}$ compared the: predatory skills of two groups of cals, one of which had been raised normally with siblings, the other of which had additionally been given objects to play with as kittens. A fine-grained analysis of the cats' subsequent predatory behaviour was used, but of the 25 frequency and latency measures of different categories of predatory behaviour usied on four different types of prey, only 5 out of 100 showed significant differences - no more that would be expected by chance!

Lack of consistent positive results in play deprivation studies as well as difficulties involved in the execution and interpretation of these experiments has forced examination of the correlation between play and behavioural skills. Yet here again, results are equivocal. In a study of young coyotes, no correlation was found between the frequency of play behaviour and subsequent predation, but the number of animals tested was small and measures of predatory skills crude $^{21}$. Similarly, no relationship was found between any measure of predatory behaviour in grasshopper mice (Onychomys leucogaster) presented with crickets and earlier differences in play behaviour when the mice lived in social groups ${ }^{22}$. Recently, social play in marmosel (Callithrix jacchus) infants was correlated with the infants' ability to gain access to food in a number of different ways including those involving social interactions ${ }^{23}$. Although only a few correlations were found, these were between play and manipulatory skills at 11 and 14 weeks of age, suggesting that certain benefits of play may have been short term in nature. In general, correlational studies only reinforce the finding that play may not be necessary for predatory skills to develop in many species.

How can the lack of positive results be explained in these and other studies? Most theories about the functions of play assume that play has immediate costs and delayed benefits. In Fig. la the outcome variable (a measure of the 'serious' behaviour presumed to be practised by playing, e.g. predatory behaviour) is shown as a function of age for two hypothetical individuals: one with play experience and one without such experience. (Adult behaviour is assumed to develop in the complete absence of play since most practice hypotheses now postulate that play only improves skills.) If experimental studies measured the outcome variable at age 2 in Fig. 1 then no differences between 'play' and 'no-play' groups would emerge. However, there are no strong theoretical reasons for assuming that benefits of play would necessarily be delayed in ontogeny, particularly since earlier benefits would have a greater selective advantage given that mortality is occurring. Figure $\mathrm{lb}$ shows play having immediate benefits, as has been found in some child studies ${ }^{24}$; if the outcome variable was measured at points 3 or 4 , no differences would be found, although some reproductive consequences might emerge at point 4. Last, if play accelerates development (Fig. Ic), again no differences would be detected in the outcome variable at point 4 . In short, lack of positive results in studies of play may have resulted from measuring play's putative effects at the wrong age, and no study has yet compared the reproductive success of individuals with the extent of their play.

Further reasons why it has proved difficult to detect possible consequences of play later in ontogeny could be because many factors normally influence the way

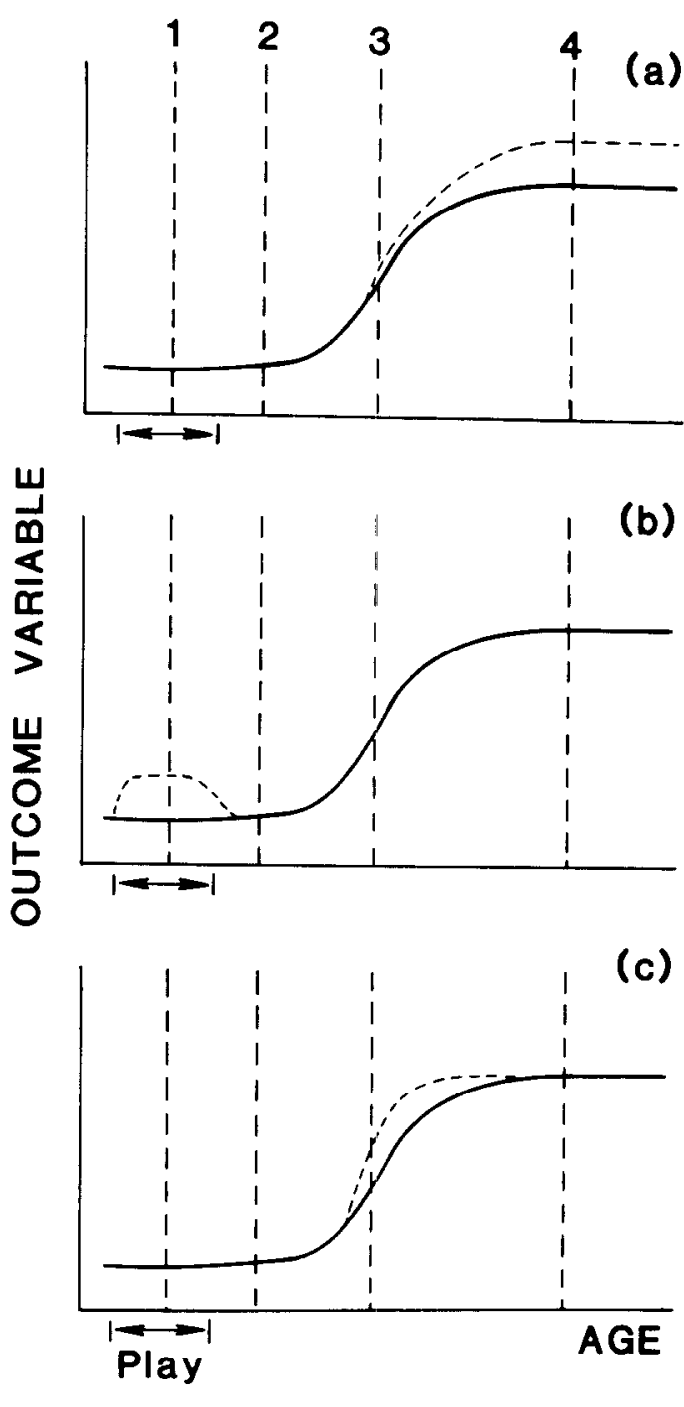

Fig. 1. Postulated differences in a behavioural outcome variable (a measure of the 'serious' behaviour) between playing (dotted line) and non-playing (continuous line) subjects as a function of age. (a) Conventional practice model: long-term benefits. (b) Immediate benefits only. (c) Acceleration of normal development: short-term benefits. Reproduced, with permission, from Ref. 3.

that behaviour develops ${ }^{25}$. For example, predatory competence in adult cats is enhanced by manipulating prey as a kitten, by the predatory behaviour of the kitten's mother in the presence of prey, and by exposure to prey when the cats are adult ${ }^{3}$. If the opportunity for one of these factors to act was not present during ontogeny (e.g. play with prey), other influences, such as increased attention paid to prey, might compensate instead so that incompetent predatory skills might never be detected in individuals with reduced opportunities for play.

Second, if play improved the efficiency and stamina of skeletal muscles and cardiovascular system, individual effects might be extremely difficult to measure, although the summed effects of 

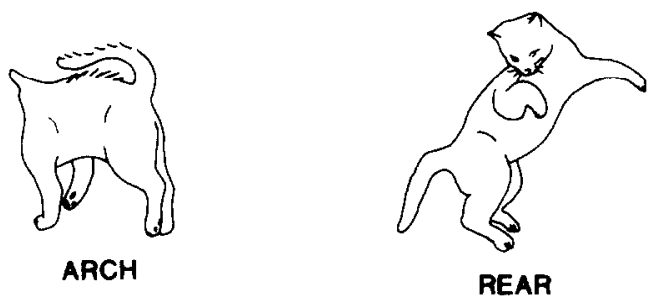

REAR

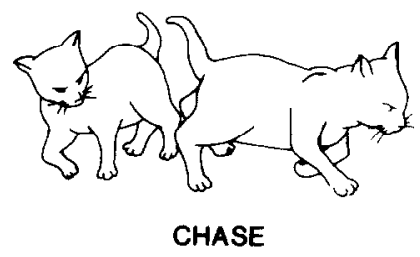

and associated with

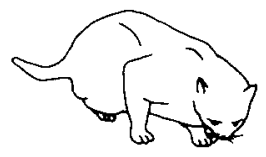

APPROACH

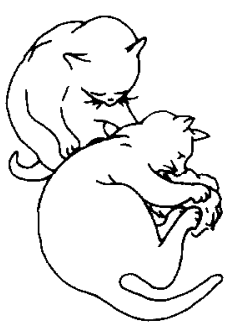

PAW

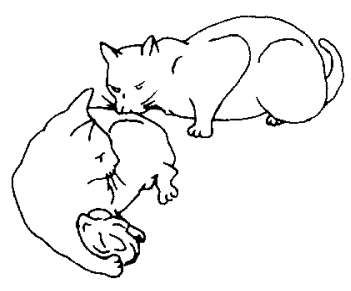

BITE

\section{patterns of predatory behaviour during kitten development}

Fig. 2. Patterns of social play that become increasingly associated with or dissociated from predatory behaviour as kittens grow older.

many small improvements would constitute a selective advantage. Third, play might only exert effects on behaviour if the animal has already reached a certain level of competence. Thus, studies should provide animals with opportunities to practise, say, predatory skills when they are young, as well as opportunities to play, in order to detect later differences in predatory behaviour between playing and non-playing groups.

Last, some sorts of play might serve as practice for structurally dissimilar forms of behaviour that are not normally examined in empirical studies. Indeed, correlational evidence shows that certain motor patterns in the social play of kittens lapproach, paw, bite) become increasingly associated with a variety of structurally different predatory behaviour patterns, while others (arch, rear, chase) become dissociated from predation and may be increasingly influenced by those factors that control agonistic behaviour ${ }^{26}$ (Fig. 2 ). These conclusions suggest that future studies are going to have to use a number of fine-grained, sensitive measures of different outcome variables and vary the opportunities for play in more subtle ways.

\section{Costs}

The tentative results from empirical studies of the adaptive significance of play have focused attention on its costs: if costs are small, it is conceivable that play might have only marginal benefits and so account for the frequently observed negative results. Using both time-lapse photography and time sampling techniques, Martin ${ }^{27}$ showed that under ideal conditions ten-week old domestic kittens, known to be particularly playful, played for only $9 \%$ of the day. By defining the energy cost of play as the net daily energy expenditure (in excess of resting metabolism) expressed as a percentage of the total energy budget, he estimated the energy cost to be only $2.5-15 \%$ for a variety of mammals ${ }^{28}$. Calculations were given added weight by measurements on kittens using indirect calorimetry, which showed that play accounted for between 4 and $9 \%$ of daily energy expenditure 27 .

In contrast, several field studies indicate that animals fail to play in times of nutritional stress, suggesting that play is energetically costly. Lee $^{29}$ found that play in juvenile vervet monkeys (Cercopithecus aethiops) in Kenya drops sharply with declining food quality in the dry season (Fig. 3); squirrel monkeys fail to play when their preferred foods are unavailable ${ }^{17}$; young voles (Microtus agrestis) born in autumn seldom play, in contrast to those born in spring and summer ${ }^{30}$; and play is extremely infrequent in harp seals, which grow very rapidly during a short period of lactation ${ }^{12}$. At present, conclusions about the energy costs of play remain equivocal.

Data on the survivorship costs of play are more consistent though less quantitative. As studies of wild and captive animals accumulate, it is apparent that play has diverse detrimental effects on juveniles across a wide array of mammals (Table 1), including humans (Fig. 4), but the extent of such incidents during individual ontogenies and across populations is unknown. Quantification of survivorship costs will only be possible with new field studies that concentrate on the behaviour of young animals. For example, cheetah (Acinonyx iubatus) cubs caused $1.5 \%$ of their mothers' hunts to fail because their play alerted the prey to the cheetahs' presence $^{31}$. This represented $5 \%$ of the time these afflicted mothers spent hunting and had the effect of causing all family members to experience longer intervals between meals and a lower rate of food intake, aside from the energy costs of playing per se.

In summary, the low costs of play found in Martin's laboratory study need to be reconciled with field and naturalistic studies showing that play drops out of the repertoire in periods of nutritional stress; and survival and time costs of play require further investigation. It is no longer possible, however, to argue that the benefits of play must be great simply on the assumption that its costs are great.

\section{What is play 'designed' for?}

The most promising line of research into the adaptive significance of play has consisted of observational studies of young animals. Four related pieces of evidence support the proposition that play serves as practice for adult motor skills.

(1) Across species, differences in play reflect differences in adult behaviour: crab-eating fox cubs (Cerdocyon thous) engage in extensive solitary object play and hunt individually as adults, whereas bush dog pups (Speothus venaticus) share rather than compete for 
ob ects and as adults hunt in social grc ups ${ }^{34}$. Again, two sympatric species of hyrax, Procavia johnstoni and Heterohyrax brucei, play at different rates when young, reflecting different rates of adult interaction involving structurally similar be aviour patterns ${ }^{35}$. These data show that qualitative and quantitative differences in species' play milror differences in species' adult be naviour.

(2) Numerous studies show that male mammals play at higher rates, exhibit different sorts of play and play more roughly than do females $^{14}$. For instance, in scimitar.horned oryx calves (Oryx dainmah) ${ }^{36}$ and domestic cats ${ }^{37}$, males in all-male groups play for longer and at higher rates, respectively, than females in all-female groups; young male ferrets (Mustela furol perform more neck-bites during play than do females ${ }^{38}$; and female yearling marmots (Marmota flaviventris) are more likely to be found on the bottom in wrestling bouts and terminate bouts more often than males ${ }^{39}$. All these data have been interpreted as being corisistent with the hypothesis that males should play more frequently so as to develop the physical strength, endurance and fighting

"able 1. Examples of survival costs of play

\begin{tabular}{|c|c|}
\hline Category & Examples \\
\hline $\begin{array}{l}\text { Reduction of } \\
\text { lood intake }\end{array}$ & Cheetah $^{31}$ \\
\hline $\begin{array}{l}\text { Separation } \\
\text { Irom mother }\end{array}$ & $\begin{array}{l}\text { Chimpanzee, } \\
\text { Japanese } \\
\text { macaque, bighorn } \\
\text { sheep }{ }^{1} \text {; cheetah } \\
\text { (pers. obs.) }\end{array}$ \\
\hline
\end{tabular}

Movement Australian sea lion into hamadryas baboon, hazardous African elephant ${ }^{1}$;

situation Siberian ibex ${ }^{32}$. domestic cat ${ }^{33}$

Increased Vervet monkey'; proximity to Thomson's gazelle predators (pers.obs.)

Provocation Japanese macaque, of severe black-tailed deer

aggression

Self injury Ring-tailed lemur, vicuna, bighorn sheep ${ }^{1}$; cheetah (pers.obs.) skills necessary for intrasexual combat as adults.

(3) Males also play more with males than they do with females. Both yearling male marmots and male Siberian ibex kids (Capra ibex $)^{40}$ initiate more play bouts with other males than would be expected by chance, and males of the latter species also play with yearling females, ignoring younger females. It is argued that play with an equal-sized or slightly larger partner, as between males in a dimorphic species, provides better motor training than play with an individual of very different size, and that this has more important consequences for males, who realize reproductive success through contests with other males. The fact that partner preferences exist in the contact play of bighorn lambs (Ovis canadensis), but not during locomotor or running play which could rehearse antipredator behaviour ${ }^{4}$, tends to support this argument.

Lack of partner preferences among female marmots has been used as evidence against play being a mechanism to strengthen social bonds and delay dispersal, as might be expected in species such as this, in which females form matrilineal social groups and yearling females are philopatric ${ }^{39}$ (but see Ref. 42).

(4) Last Byers ${ }^{43}$ showed that cap tive ibex kids played more on sloping terrain than on flat surfaces, and this was most apparent during locomotor play, suggesting that play serves as physical training for an adult life moving over precipitous areas.

Taken together, the data presented above suggest that at least one of play's functions is to improve in some way the fighting skills necessary for males in polygynous mammals.

Arguments based on the design of play are difficult to interpret because they only show that play has the structural properties necessary for performing a particular function, not that it does perform that function. Moreover, they do not easily distinguish hypotheses from each other. Males might play together to practise motor skills more effectively; or to thicken growing bone, physically train muscles and increase cardiopulmonary capacity
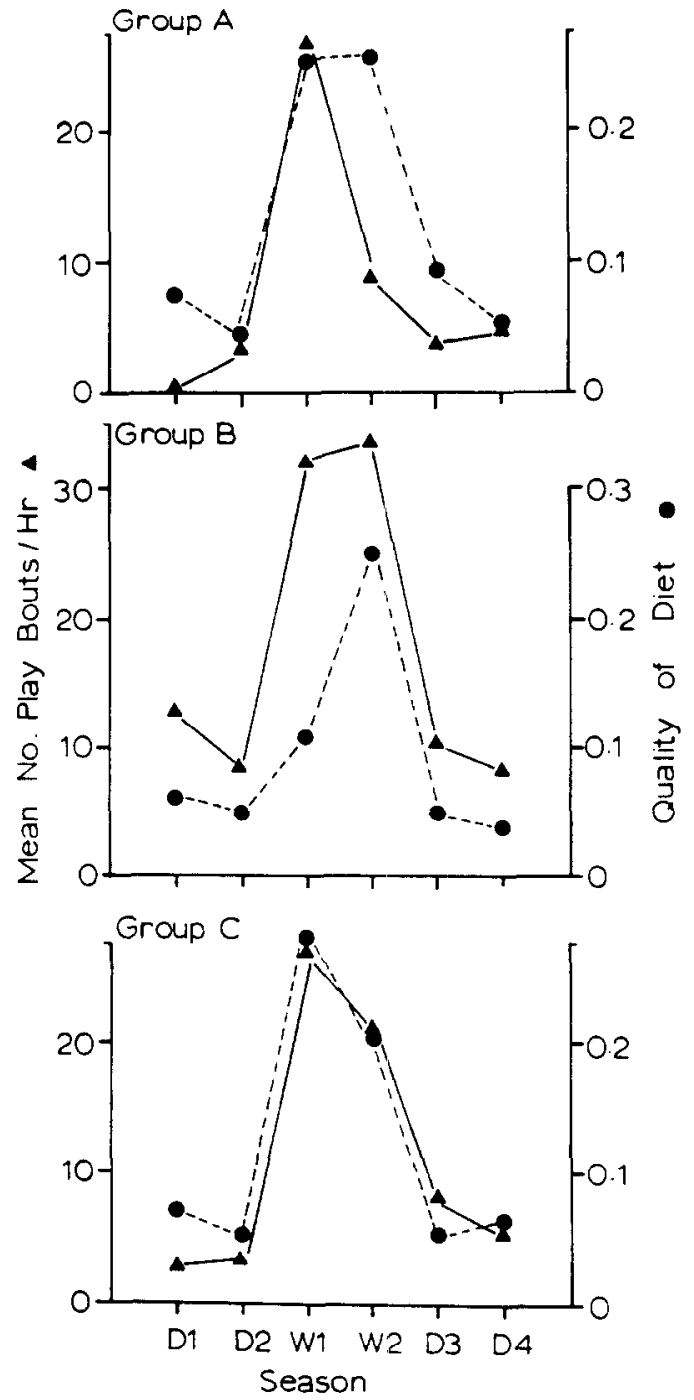

Fig. 3. Mean number of play bouts per hour plotted with measures of dietary quality against three-month seasonal periods, for three groups of vervet monkeys ( $W=$ wet, $D=$ dry season $)$. Dietary quality was measured as the ratio of protein $(\mathrm{g})$ over gross calories per wet weight intake for each of the foods composing the top ten in all seasonal periods, multiplied by the percentage of those foods in the diet in six separate seasonal periods. Weighted ratios were then summed to derive a seasonal estimate of dietary quality. Reproduced, with permission, from Ref. 29.

more efficiently; or to enhance competency in social dealings with other males; or any combination of these. In addition, lack of an association between the design of play

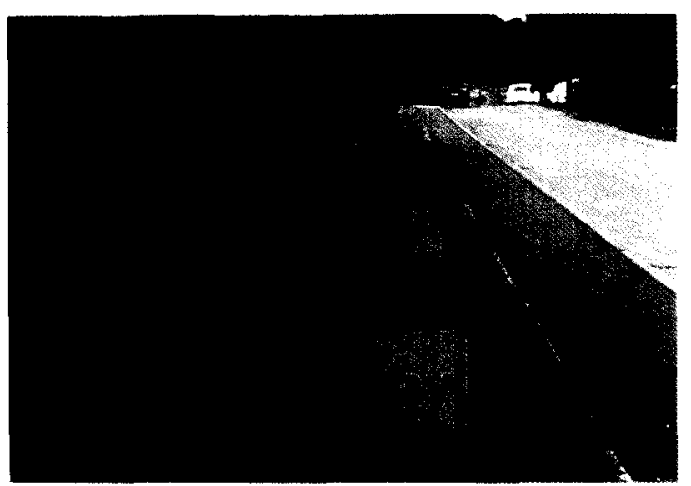

Fig. 4. Societies in the western world assume that play in children is costly; this road sign warns drivers that playing children may not notice vehicles. 
and adult skills cannot refute a hypothesis conclusively: although Symons ${ }^{44}$ has argued that absence of agonistic signals from the social play of rhesus monkeys (Macaca mulattal, and the presence of play signals that are not seen in fighting, make aggressive social play an 'unpromising candidate' as a means of practising communication skills, such deft reasoning requires further empirical work to give it necessary added weight.

Information on the adaptive significance of play is tentative at best. Nevertheless, attempts are now being made to measure the costs of play across different species. An increasing number of studies are using observational data in a sophisticated way to argue that play is designed to practise motor skills and to train young animals physiologically. Observations on free-living animals can do much to guide experimental studies because they can indicate those behaviour patterns for which direct practice is difficult or dangerous and thus might be rehearsed through play. Furthermore, future experimental and correlational studies necessary to support the positive findings based on 'arguments from design' are in a good position to learn from the pitfalls encountered in previous empirical work on play, and now have a number of strong leads to follow.
Acknowledgements

1 thank Montse Gomendio, Meg Symington and referees for comments on the manuscript.

\section{References}

1 Fagen, R. (1981) Animal Play Behavior, Oxford University Press

2 Smith, P.K. (1982) Behav. Brain Sci

$5,139-184$

3 Martin, P. and Caro, T.M. (1985) Adv. Study Behav. 15, 59-103

4 Groos, K. (1898) The Play of Animals (first published Basel 1896), Appleton

5 Loizos, C. (1967) in Primate Ethology

(Morris, D., ed.), pp. 176-218, Weidenfield $\varepsilon$ Nicholson

6 Henry, J.D. and Herrero, S.M. (1974) Am. Zool. 14, 371-389

7 Hill, H.L. and Bekoff, M. 119771 Anim Behav. 25, 907-909

8 Fry, D.P. (1987) Ethol. Sociobiol. 8, 285-306 9 Caro, T.M., Roper, R., Young, M. and Dank. G.R. ( 1979) Behaviour 69, 303-315 10 Barrett, P. and Bateson, P. (1978) Behaviour 66, 106-120

11 Bekoff, M. and Byers, J.A. (1981) in Behavioral Development IImmelmann, K. Barlow, G.W., Petrinovich, L. and Main, M. eds), pp. 296-337, Cambridge University Press

12 Kovacs, K.M. 11987 ) Anim. Behav. 35 844-855

13 Rasa, O.A.E. (1984) Anim. Behav. 32 579-589

14 Meaney, M.I., Stewart, I. and Beatty, W.W. (1985) Adv. Study Behav. 15, 1-58 15 Baldwin, J.D. and Baldwin. J.I. (1977) in Primate Bio-social Development (ChevalierSkolnikoff, S. and Poirier, F.E.. edsl, pp. 343-406, Garland

16 Thomas, E. and Schaller, F. (1954) Naturwissenschaften 41,557-558

I Iranslation in Muller-Schwarze, D., ed

(1978) Evolution of Play Behavior, Dowden,
Hutchinson $\varepsilon$ Ross

17 Baldwin, J.D and Baldwin, J.I. 1 1974) Am. Zool. 14, 303-315

18 Einon, D.F., Morgan, M.J. and Kibbler, C.C. (1978) Dev. Psychobiol. 11, 213-225

19 Einon, D.F. and Morgan, M.). (1977) Dev. Psychobiol. 10, 123-132

20 Caro, T.M. (1980) Behav. Neural Biol. 29. 29-51

21 Vincent, L.E. and Bekoff, M. (1978) Anim. Behav. 26, 225-231

22 Davies, V.A. and Kemble. E.D. 11983

Behav. Process. 8, 197-204

23 Chalmers, N.R. and Locke-Haydon,

11984) Dev. Psychobiol. 17, 191-208

24 Simon, T. and Smith, P.K. (1983) Br. I. Dev. Psychol. 1, 289-297

25 Bateson, P.P.G. 119761 in Growing Points in Ethology (Bateson, P.P.G. and Hinde, R.A eds), pp. 401-421, Cambridge University Press

26 Caro, T.M. (1981) Behavior 70, I-24

27 Martin, P. 119841 Z. Tierpsychol. 64.

298-392

28 Martin. P. (1982) Anim. Behav. 30, 294-295

29 Lee, P.C. (1984) Behavior 91, 245-262

30 Wilson, S. 119731 Zool. I. Linn. Soc. 52 ,

$45-62$

31 Caro, T.M. (1987) Anim. Behav. 35, 257-25)

32 Byers, I.A. (1987) Nat. Hist 96, 15), 54-61

33 Martin, P. and Bateson, P. (1985) Anim.

Behav. 33, 502-510

34 Biben, M. (1982) Behavior 79, 201-2)1

35 Caro, T.M. and Alawi, R.M. (1985) Behavior 95, 87-109

36 Pfeifer. S. $11985 \mid Z$. Tierpsychol 69 , 281-292

37 Caro, T.M. (1981) Anim. Behav. 29, 271-27c 38 Biben, M. (1982) Biol. Behav. 7, 303-308 39 lamieson, S.H and Armitage, K.B. 119871

Z. Tierpsychol. 74, 237-253

40 Byers, J.A. (1980) Z. Tierpsychol. 53,23-40

41 Berger, J. (1980) /. Zool. 192, 531-542

42 Wilson, S. (1973) Behavior 48, 37-60

43 Byers, J.A. (1977) Z. Tierpyschol. 45.

199-200

44 Symons, D. 119741 Am. Zool. 14, 317-322

\section{Letters to the Editor}

\section{Spatial Scale and Plant Species Richness}

I enjoyed reading the recent paper in TREE by Auerbach and Shmida ${ }^{1}$, and liked their conceptually useful Figure 1, which showed a species-area curve from $10^{-1}$ to $10^{15} \mathrm{~m}^{2}$, and their choice of factors contributing to species richness at each scale. What puzzled me was their choice of trophic equivalency as the dominant factor for areas greater than $10^{9} \mathrm{~m}^{2}$. Their argument for its dominance at regional to continental scales $\left(10^{9}\right.$ $10^{13} \mathrm{~m}^{2}$ ) required topographic and geographic barriers to dispersal at these scales. Studies of vegetation changes during the past 18000 years ${ }^{2,3}$ show that such features are not barriers over this time span at scales up to $10^{13} \mathrm{~m}^{2}$ and that en- vironmental heterogeneity must be a key factor in these large areas ${ }^{4}$.

At scales of $10^{5}-10^{12} \mathrm{~m}^{2}$, plant species sort out their location within their range limits. Individuals within a species survive in some habitats but not in others, and Auerbach and Shmida are correct in noting the importance of habitat heterogeneity at these micro- and meso-scales. At scales of $10^{9}-10^{15} \mathrm{~m}^{2}$, species range limits are crossed. Trophic equivalency does not explain why these range limits exist, but the presence of range limits is the reason that species richness increases at areas larger than $10^{9} \mathrm{~m}^{2}$. Factors limiting species ranges must be considered if we are to explain species richness over areas greater than $10^{9} \mathrm{~m}^{2}$.

Knowledge of how environmenta factors limit species distributions are key to any understanding of specie: richness. A recent book b) Woodward ${ }^{5}$ explores some of the climatic factors controlling broad scale vegetational patterns. Fo spatial scales of $10^{11}-10^{13} \mathrm{~m}^{2}$ macroclimatic heterogeneity and the climatic limitations on species ranges are probably the dominan factors determining species rich ness. Only at intercontinental anc global scales are topographic anc geographic barriers sufficientl permanent that similar macroclima tic regions contain different groups of species (e.g. the Mediterranear 